\title{
Agências regulatórias e federalismo: a gestão descentralizada da regulação no setor de energia*
}

\author{
Cecília Olivieri**
}

SUMÁRIO: 1. Introdução; 2. A descentralização do modelo de agências regulatórias; 3. A disputa pela descentralização do poder de regular e fiscalizar; 4. A gestão da descentralização.

SUMMARY: 1 . Introduction; 2 . The decentralization of the regulatory agency model; 3 . The dispute over the decentralization of the power to regulate and oversee; 4. Decentralization management.

Palavras-CHAVE : regulação; agências estaduais; federalismo; descentralização; gestão.

KEY WORDS : regulation; state agencies; federalism; decentralization; management.

Este artigo explora o tema da relação entre regulação e federalismo, a partir do estudo da descentralização das atividades de regulação e fiscalização na área de energia elétrica no Brasil. O artigo faz um balanço descritivo da criação das agências nos níveis estadual e municipal, destacando o grande número de agências criadas a partir de 1997, e analisa os principais estudos sobre a origem e as características desse processo. A disputa entre União e estados sobre a criação da figura da descentralização das atividades de regulação e fiscalização foi aspecto central do processo de elaboração da lei de criação da Aneel. O artigo mostra o papel dessa disputa na formatação do desenho institucional da Aneel e afirma que ela se caracteriza como um dos fatores explicativos da gênese e da governança das agências reguladoras no Brasil, em especial na área de energia elétrica. A partir de um balanço das atividades descentralizadas de regulação e

\footnotetext{
* Artigo recebido em fev. e aceito em maio 2006.

** Doutoranda em administração pública e governo pela Eaesp/FGV, mestre em ciência política pela FFLCH/USP. Endereço: Rua Nelson Antonio, 18, ap. 10 - CEP 05417-060, São Paulo, SP. E-mail: ceciliaolivieri@gvmail.br.
} 
fiscalização na área de energia, foram levantadas questões referentes à gestão da descentralização, em relação tanto às agências subnacionais, responsáveis pelas atividades regulatórias complementares, quanto às agências nacionais, que coordenam essas atividades.

Regulatory agencies and federalism: the decentralized management of the energy sector regulation

This article explores the subject of the relationship between regulation and federalism, from the perspective of the decentralization of the regulatory activities in the electricity sector in Brazil. The article presents a descriptive assessment of the creation of the state and municipal agencies, underlining the large number of agencies created since 1997, and analyzes the main studies on this processes' origin and characteristics. The dispute between the federal and state governments over the creation of the concept of decentralization of the regulatory and overseeing activities was central to the process of elaborating the act that created Aneel (the Brazilian electricity sector regulatory agency). The article shows the role that this dispute had when Aneel's institutional design was being formatted and defends that it is one of the explaining factors for the genesis and governance of the Brazilian regulatory agencies, particularly in the electric power sector. It assesses the decentralized regulatory and overseeing activities in the power sector, and raises some issues on decentralization management, in relation both to the state agencies, responsible for the complementary regulatory activities, and the federal agencies, which coordinate these activities.

\section{Introdução}

Este artigo explora uma agenda de pesquisa no tema regulação e federalismo no Brasil, a partir do estudo da descentralização das atividades de regulação e fiscalização na área de energia elétrica. Os temas mais importantes sobre federalismo e regulação na realidade nacional atual são a difusão do modelo de agências reguladoras pelos estados e municípios, os conflitos de competência regulatória entre os níveis federal e local e os instrumentos de gestão entre as agências federais e subnacionais.

Questões federativas como a coordenação entre diferentes níveis de governo e as disputas políticas sobre a distribuição de competências têm forte influência sobre o recente processo de criação e institucionalização das agências reguladoras nos níveis federal, estadual e municipal. Essa interface entre Federação e regulação tem sido pouco estudada, apesar de que "grande parte dos desafios à institucionalização de uma nova governança regulatória no Brasil estão relacionados à questão federativa" (Melo, 2002:280). Este artigo 
contribui para estimular o debate sobre as agências subnacionais, em especial, na área das ciências sociais e administrativas, a partir do estudo do processo de inclusão da descentralização na lei que criou a Aneel em 1996.

Apesar dos desafios ao funcionamento e implementação de todas as agências federais, como a vulnerabilidade do regime regulatório a choques endógenos e exógenos, a ausência de competências plenamente definidas, a transição incompleta do modelo anterior para o novo e a insuficiente capacidade de enforcement das agências e sua autonomia em relação aos agentes envolvidos (Melo, 2002), as áreas de telecomunicação, energia e gás avançaram muito mais, em termos de transformação do status quo com a privatização e a quebra de monopólio, do que as outras agências da área de infraestrutura - como água e transportes - nas quais concessões federais e estaduais não deslancharam devido a conflitos de competências, indefinição do marco regulatório e falta da articulação entre as esferas governamentais.

Ainda há conflitos de competência a serem solucionados, em especial nas áreas de saneamento e água, e isso tem atrasado a definição de marcos regulatórios e a consolidação da atuação das agências nessas áreas. O avanço do processo de regulamentação e institucionalização das agências nas áreas de água e saneamento e de transportes terrestres e aquáticos não depende de questões relacionadas à natureza do serviço nem à vontade política, mas do tratamento de problemas de origem federativa, como acordos sobre distribuição de competências e criação de mecanismos de articulação setorial e regional. "[A] interface entre regulação e Federação varia amplamente conforme o setor o que adiciona grande complexidade à questão" (Melo, 2002:280).

Na primeira parte deste artigo é feito um balanço descritivo da criação das agências estaduais e municipais, no qual se destacam o grande número de agências criadas a partir de 1997 e a falta de análises mais detalhadas e específicas sobre a origem e as características desse processo.

Na segunda parte, é analisado o processo de elaboração da lei de criação da Aneel, com destaque para a disputa entre União e estados sobre a criação da figura da descentralização das atividades de regulação e fiscalização. Pretendemos mostrar o papel dessa disputa na formatação do desenho institucional da Aneel, e afirmar que ela se caracteriza como um dos fatores explicativos da gênese e da governança das agências reguladoras no Brasil, em especial na área de energia elétrica.

Na terceira parte, está um balanço das atividades descentralizadas de regulação e fiscalização na área de energia, com o objetivo de levantar questões referentes à gestão da descentralização, tanto em relação às agências subnacionais, responsáveis pelas atividades regulatórias complementares, quanto em relação às agências nacionais, que coordenam essas atividades. 


\section{A descentralização do modelo de agências regulatórias}

Foram criadas 23 agências, em 18 estados, entre 1997 e 2005, conforme o quadro 1. A grande maioria é de agências estaduais (91,3\%), existindo apenas duas agências municipais, ambas na área de saneamento, em Joinville, Santa Catarina, e em Cachoeiro de Itapemirim, no Espírito Santo.

Alguns estados têm mais de uma agência, cada uma delas especializada em uma área de atuação. É o caso de São Paulo e Rio de Janeiro, com agências especializadas em energia e em transportes, e da Paraíba, com agências nas áreas de energia, vigilância sanitária e gestão de águas.

\begin{tabular}{|c|c|c|c|}
\hline \multicolumn{4}{|c|}{ Quadro 1} \\
\hline Agência & Nome & Ente & Lei e data de criação \\
\hline Agergs/RS & $\begin{array}{l}\text { Agência Estadual de Regulação } \\
\text { dos Serviços Públicos Delegados } \\
\text { do Rio Grande do Sul }\end{array}$ & Estadual & $\begin{array}{l}\text { Lei } n^{0} 10.931 \text {, de } 9 \text { de janeiro } \\
\text { de } 1997\end{array}$ \\
\hline Arsep/RJ & $\begin{array}{l}\text { Agência Reguladora de Serviços } \\
\text { Públicos Concedidos do Estado } \\
\text { do Rio de Janeiro }\end{array}$ & Estadual & $\begin{array}{l}\text { Lei } n^{0} 2.686 \text {, de } 13 \text { de fevereiro } \\
\text { de } 1997\end{array}$ \\
\hline CSPE/SP & $\begin{array}{l}\text { Comissão de Serviços Públicos } \\
\text { de Energia (São Paulo) }\end{array}$ & Estadual & $\begin{array}{l}\text { Lei Complementar n- 833, de } 17 \\
\text { de outubro de } 1997\end{array}$ \\
\hline Arce/CE & $\begin{array}{l}\text { Agência Reguladora de Serviços } \\
\text { Públicos Delegados do Estado do Ceará }\end{array}$ & Estadual & $\begin{array}{l}\text { Lei } n^{0} 12.786 \text {, de } 30 \text { de dezembro } \\
\text { de } 1997\end{array}$ \\
\hline Arcon/PA & $\begin{array}{l}\text { Agência Estadual de Regulação } \\
\text { e Controle de Serviços Públicos }\end{array}$ & Estadual & $\begin{array}{l}\text { Lei } \text { n}^{0} 6.099 \text {, de } 30 \text { de dezembro } \\
\text { de } 1997\end{array}$ \\
\hline Agerba/BA & $\begin{array}{l}\text { Agência Estadual de Regulação de } \\
\text { Serviços Públicos de Energia, } \\
\text { Transportes e Comunicações da Bahia }\end{array}$ & Estadual & Lei $n^{0} 7.314$, de 1998 \\
\hline Ases/SE & $\begin{array}{l}\text { Agência Reguladora de Serviços } \\
\text { Concedidos do Estado de Sergipe }\end{array}$ & Estadual & $\begin{array}{l}\text { Lei } n^{0} 3.973 \text {, de } 10 \text { de junho } \\
\text { de } 1998\end{array}$ \\
\hline Arse/MG & $\begin{array}{l}\text { Agência Reguladora de Serviços } \\
\text { Públicos do Estado de Minas Gerais }\end{array}$ & Estadual & $\begin{array}{l}\text { Lei } n^{0} 12.999 \text {, de } 31 \text { de julho } \\
\text { de } 1998\end{array}$ \\
\hline Agersa/ES & $\begin{array}{l}\text { Agência Municipal de Regulação dos } \\
\text { Serviços de Saneamento de Cachoeiro } \\
\text { de Itapemirim }\end{array}$ & Municipal & Lei $n^{0} 4.798$, de 1999 \\
\hline Ager/MT & $\begin{array}{l}\text { Agência Estadual de Regulação dos } \\
\text { Serviços Públicos Delegados do } \\
\text { Estado do Mato Grosso }\end{array}$ & Estadual & $\begin{array}{l}\text { Lei } n^{0} 7.101 \text {, de } 14 \text { de janeiro } \\
\text { de } 1999\end{array}$ \\
\hline
\end{tabular}

continua 


\begin{tabular}{|c|c|c|c|}
\hline Agência & Nome & Ente & Lei e data de criação \\
\hline Arsep/RN & $\begin{array}{l}\text { Agência Reguladora de Serviços } \\
\text { Públicos do Rio Grande do Norte }\end{array}$ & Estadual & $\begin{array}{l}\text { Lei } n^{0} 7.463 \text {, de } 2 \text { de março } \\
\text { de } 1999\end{array}$ \\
\hline AGR/G0 & $\begin{array}{l}\text { Agência Goiana de Regulação, } \\
\text { Controle e Fiscalização de } \\
\text { Serviços Públicos }\end{array}$ & Estadual & $\begin{array}{l}\text { Lei } n^{0} 13.550 \text {, de } 11 \text { de novembro } \\
\text { de } 1999\end{array}$ \\
\hline Arsam/AM & $\begin{array}{l}\text { Agência Reguladora dos Serviços } \\
\text { Públicos Concedidos do Estado } \\
\text { do Amazonas }\end{array}$ & Estadual & $\begin{array}{l}\text { Lei } n^{0} 2.568 \text {, de } 25 \text { de novembro } \\
\text { de } 1999\end{array}$ \\
\hline Amae/SC & $\begin{array}{l}\text { Agência Municipal de Regulação } \\
\text { dos Serviços de Água e Esgotos de } \\
\text { Joinville }\end{array}$ & Municipal & Lei $n^{0} 4.341$, de 2001 \\
\hline Arpe/PE & $\begin{array}{l}\text { Agência Estadual de Regulação dos } \\
\text { Serviços Públicos Delegados do } \\
\text { Estado de Pernambuco }\end{array}$ & Estadual & $\begin{array}{l}\text { Lei } n^{0}-11.742 \text {, de } 14 \text { de janeiro } \\
\text { de } 2000\end{array}$ \\
\hline Arsal/AL & $\begin{array}{l}\text { Agência Reguladora de Serviços } \\
\text { Públicos do Estado de Alagoas }\end{array}$ & Estadual & $\begin{array}{l}\text { Lei n- } 6.267 \text {, de } 20 \text { de setembro } \\
\text { de } 2001\end{array}$ \\
\hline Agepan/MS & $\begin{array}{l}\text { Agência Estadual de Regulação } \\
\text { dos Serviços Públicos de Mato } \\
\text { Grosso do Sul }\end{array}$ & Estadual & $\begin{array}{l}\text { Lei } n-2.363 \text {, de } 19 \text { de dezembro } \\
\text { de } 2001\end{array}$ \\
\hline Artesp/SP & $\begin{array}{l}\text { Agência Reguladora de Serviços } \\
\text { Públicos Delegados de Transportes } \\
\text { do Estado de São Paulo }\end{array}$ & Estadual & $\begin{array}{l}\text { Lei n- } 914 \text {, de } 14 \text { de janeiro } \\
\text { de } 2002\end{array}$ \\
\hline Agevisa/PB & $\begin{array}{l}\text { Agência Estadual de Vigilância } \\
\text { Sanitária da Paraíba }\end{array}$ & Estadual & $\begin{array}{l}\text { Lei } n^{0} 7.069 \text {, de } 12 \text { de abril } \\
\text { de } 2002\end{array}$ \\
\hline Ageel/PB & $\begin{array}{l}\text { Agência Estadual de Energia } \\
\text { da Paraíba }\end{array}$ & Estadual & $\begin{array}{l}\text { Lei } n^{0} 7.120 \text {, de } 28 \text { de junho } \\
\text { de } 2002\end{array}$ \\
\hline Agenersa/RJ & $\begin{array}{l}\text { Agência Reguladora de Energia } \\
\text { e Saneamento Básico do Estado } \\
\text { do Rio de Janeiro }\end{array}$ & Estadual & $\begin{array}{l}\text { Lei } n^{0} 4.556 \text {, de } 6 \text { de junho } \\
\text { de } 2005\end{array}$ \\
\hline Agetransp/RJ & $\begin{array}{l}\text { Agência Reguladora de Serviços } \\
\text { Públicos Concedidos de Transportes } \\
\text { Aquaviários, Ferroviários, } \\
\text { Metroviários e de Rodovias do } \\
\text { Estado do Rio de Janeiro }\end{array}$ & Estadual & $\begin{array}{l}\text { Lei n- } 4.555 \text {, de } 6 \text { de junho } \\
\text { de } 2005\end{array}$ \\
\hline Aesa/PB & $\begin{array}{l}\text { Agencia Executiva de Gestão das } \\
\text { Águas do Estado da Paraíba }\end{array}$ & Estadual & Lei $\mathrm{n}^{0} 7.779$, de 7 de julho de 2005 \\
\hline
\end{tabular}

A descentralização do modelo de agências está ligada ao movimento das recentes privatizações e ao forte estímulo do governo federal, na gestão de Fernando Henrique Cardoso, pela adoção da privatização e do modelo de agências para a gestão das concessões e a fiscalização dos serviços privatizados. Segundo Melo (2002:282), 
O papel da União como agente indutor da difusão da nova forma institucional foi fundamental, se manifestando ativamente, sobretudo no caso dos governos da coalizão política do Executivo federal [da gestão entre 1994 e 2002], na forma de indução ativa e financiamento das privatizações e dos programas estaduais de reforma do setor público. As agências regulatórias federais, por sua vez, contribuíram indiretamente de forma também importante nessa difusão, mediante convênios e esquemas de cooperação os mais variados, e que tiveram grande expressão no setor elétrico.

Outra característica desse processo de descentralização do modelo das agências é a fragilidade institucional das agências estaduais, pelo fato de muitas delas terem sido criadas após a privatização das empresas ou dos serviços públicos, e por não terem autonomia em relação aos governos, conforme o levantamento realizado pelo Programa Nacional de Apoio à Modernização da Gestão dos Estados Brasileiros e do Distrito Federal (Pnage, 2003:54) em todos os estados em 2003:

O que salta à vista (...) é que há um certo descompasso entre o processo de privatização e a criação/estruturação das agências reguladoras. Houve 18 estados que privatizaram empresas, ao passo que foram constituídas 16 agências reguladoras [até 2003]. Decerto que é um pequeno descompasso, mas dado que os governos estaduais apresentaram informações precárias sobre sua estrutura regulatória, é possível - embora indesejável - que esta diferença também seja ainda maior no plano qualitativo, isto é, pode haver apenas um pequeno número de estados com adequada estrutura regulatória. O fato é que houve um aumento considerável de serviços públicos sob regulação (e não execução direta) estatal e é preciso preparar as administrações estaduais para dar conta deste problema.

Essas avaliações de caráter geral precisam ser enriquecidas por estudos dos casos específicos. As agências continuaram a ser criadas mesmo após o fim da gestão FHC e a cessação dos incentivos oferecidos pelo governo federal à criação das agências. Em 2005, foram criadas três agências estaduais, a Aesa na Paraíba e duas agências setoriais no Rio de Janeiro. Qual a dinâmica dessas iniciativas, considerando que nesses estados já havia experiências anteriores, uma multissetorial no Rio de Janeiro e duas setoriais na Paraíba?

Além disso, ainda há poucos estudos sobre a atuação das agências estaduais e municipais. Uma característica das agências estaduais ainda não analisada é a diferença quanto às suas competências. Mais da metade $(56,5 \%)$ 
das agências subnacionais são multissetoriais, ou seja, regulam e fiscalizam todos os serviços públicos privatizados, enquanto as demais são especializadas em determinadas áreas, como energia, saneamento e transporte, conforme a tabela 1. No nível federal, o modelo que se configurou foi o de agências especializadas, enquanto no nível subnacional parece estar se configurando um modelo de agências multissetoriais.

\begin{tabular}{|lcc|}
\hline \multicolumn{3}{c|}{ Tabela 1 } \\
\multicolumn{3}{|c|}{ Agências subnacionais quanto à área de atuação } \\
\hline Área de atuação da agência & Quantidade & Percentual \\
\hline Multissetorial & 13 & 56,5 \\
Gás e energia elétrica & 2 & 8,7 \\
Transporte & 2 & 8,7 \\
Saneamento e/ou abastecimento de água & 2 & 8,7 \\
Energia, transportes e comunicação & 1 & 4,3 \\
Recursos hídricos & 1 & 4,3 \\
Controle sanitário & 1 & 4,3 \\
Gás e saneamento & 1 & 4,3 \\
Total & 23 & 100,0 \\
\hline
\end{tabular}

Pouco se sabe sobre as agências municipais criadas até o momento, além do fato de atuarem na área de saneamento. Essa é uma das áreas em que existe maior dificuldade no estabelecimento de marcos regulatórios, devido à necessidade de coordenação intersetorial e intergovernamental. Várias instâncias do governo federal e dos governos subnacionais estão envolvidas na regulação do setor de saneamento, exigindo coordenação e articulação.

No nível federal, a regulação do saneamento tem interface com diversos setores, como os de planejamento e desenvolvimento urbano, meio ambiente, recursos hídricos e saúde. A definição de diretrizes para o setor de saneamento básico depende da elaboração e implementação da política nacional de desenvolvimento urbano, ainda que esta não exerça influência sobre a prestação dos serviços de saneamento. A área de meio ambiente, por sua vez, é responsável pela política nacional de recursos hídricos, definida na Lei $\mathrm{n}^{0}$ 9.433/97, que determina a gestão descentralizada dos recursos hídricos. Além disso, outros ór- 
gãos do Ministério do Meio Ambiente, ainda que não atuem diretamente na regulação dos serviços de saneamento, fazem parte do marco regulatório da área, como o Instituto Brasileiro do Meio Ambiente e dos Recursos Naturais e Renováveis (Ibama), que fiscaliza a utilização de recursos naturais, e a Agência Nacional de Águas (ANA), que implementa a política nacional de recursos hídricos (Conforto, 2000).

Outros ministérios, como o da Saúde, também estão envolvidos no marco regulatório do saneamento, pela manutenção do sistema de vigilância sanitária nacional, que atua nos três níveis de governo e é responsável, por exemplo, pela definição do padrão de potabilidade da água para consumo humano. Segundo Conforto (2000:171-172), a situação atual nessa área é "de sobreposição de tarefas com perda de qualidade e integração".

Além dessa interface interministerial e intersetorial, a regulação do saneamento envolve a interface federativa relativa à atribuição de competências entre governos federal, estaduais e municipais. Segundo a Constituição Federal, a competência no setor de serviços de abastecimento de água e de esgotamento sanitário é concorrente, ou seja, à União competem a definição de diretrizes gerais para o saneamento básico e o estabelecimento de normas de cooperação entre os entes federativos, e os estados têm competência para legislar concorrentemente em proteção do meio ambiente, vigilância sanitária, direito econômico e do consumidor. Os municípios, por sua vez, têm a titularidade dos serviços de interesse local, mas não há definição sobre a titularidade dos serviços prestados em sistemas integrados, como é o caso das regiões metropolitanas. A falta de clareza sobre a titularidade dos serviços de sistemas integrados e a falta de consolidação dos vários instrumentos legais relacionados à questão do saneamento têm dificultado os processos de concessão dos serviços para o setor privado e a realização de investimentos (Conforto, 2000).

A análise da experiência de municípios que enfrentaram a ausência de marcos regulatórios e a indefinição sobre a titularidade dos serviços, concedendo serviços na área de saneamento, mostra as dificuldades enfrentadas por essas iniciativas municipais isoladas. No município de Ribeirão Preto, em São Paulo, a prefeitura concedeu a exploração dos serviços de tratamento de esgoto sem a criação de agência reguladora, instituindo mecanismos próprios de regulação na área, com contrato de concessão, no modelo de regulação por contrato (Ferreira, 2005). A insuficiência dos termos contratuais diante de contingências, como o atraso de obras, e diante de exigências legais de outros setores, como meio ambiente, aumentam a insegurança na execução do contrato e a instabilidade na prestação do serviço. 


\section{A disputa pela descentralização do poder de regular e fiscalizar}

Uma das principais questões debatidas na época da tramitação do projeto de lei de criação da Aneel, durante o ano de 1996, foi a inclusão da figura da descentralização das atividades de regulação, fiscalização e controle para agências reguladoras estaduais. O projeto de lei enviado ao Congresso pelo Executivo não previa a possibilidade da descentralização, e a sua inclusão na lei da Aneel se deveu à negociação entre o governo federal e os estados.

Um dos principais fatores que delineou essa negociação foi a posição estratégica que os estados, circunstancialmente, ocupavam no sistema elétrico nacional. O governo federal detinha a competência sobre a regulação e operação do sistema elétrico, tanto na geração quanto na distribuição, mas a distribuição de energia elétrica estava sob controle estadual, por meio de concessões federais às empresas estaduais de energia. A privatização do setor de distribuição de energia elétrica era, a rigor, prerrogativa do governo federal, como poder concedente, mas dependia, na prática, da anuência dos governadores em abrir mão de suas empresas estaduais.

Em 1995, as empresas estaduais controlavam cerca de $80 \%$ da distribuição de energia elétrica, sendo o restante controlado pelas empresas federais Escelsa e Light (Pires, 2000). A circunstância que colocava os estados como pontos de veto no processo de privatização do setor elétrico era a decisão do governo federal de iniciar a privatização pelas empresas de distribuição, e não de geração. Como veremos a seguir, essa posição dos estados se enfraquecia devido à crise de endividamento público estadual e à situação deficitária das empresas de energia, mas a renegociação das dívidas estaduais não foi o único elemento da barganha entre as esferas de poder. O governo federal também teve que ceder a descentralização do poder de regular e fiscalizar para viabilizar as privatizações nos estados.

A decisão de iniciar a privatização pelo setor de distribuição foi tomada devido à avaliação da inviabilidade de privatizar a geração mantendo o controle estatal sobre as distribuidoras (Pires, 2000). O controle estatal das distribuidoras inibia potenciais investidores na privatização da geração devido ao histórico de calote das distribuidoras perante as empresas geradoras de energia elétrica. Esse problema era tão grave que um dos primeiros passos do processo de reestruturação do setor elétrico havia sido, em 1993, a renegociação das dívidas das empresas distribuidoras com as geradoras, que alcançavam, na época, o expressivo montante de US\$ 20 bilhões.

Além disso, as características do sistema nacional de geração, como sua grande interligação e a necessidade de coordenação da operação das usinas hidrelétricas, exigiam estudos complexos e uma extensa regulação 
para viabilizar sua privatização, os quais eram recursos institucionais inexistentes em 1995. A solução encontrada foi iniciar o processo de privatização no setor elétrico com as distribuidoras federais, com a venda da Excelsa, em julho de 1995, e da Light, em maio de 1996, e com a negociação pela privatização nos estados.

Os estados, por sua vez, tinham interesse em privatizar suas companhias de energia, mas também pretendiam manter o máximo possível de controle sobre o setor, pela descentralização da regulação. Alguns estados, como São Paulo, já haviam criado programas de desestatização e instituído órgãos precursores das agências reguladoras estaduais, para coordenar o processo de privatização tanto no setor elétrico quanto no de gás natural.

A privatização das empresas estaduais de distribuição de energia dependia de dois fatores, em que a ação do governo federal era indispensável: a renovação dos contratos de concessão federal dessas empresas e a reestruturação das empresas estaduais. O primeiro problema foi resolvido já em 1995, com a regulamentação da Lei de Concessões (Lei $\mathrm{n}$ ㅇ 8.987/95) pela Lei $\mathrm{n}^{\underline{0}}$ 9.074/95, que permitiu a renovação das concessões federais às empresas estaduais de distribuição.

Os empréstimos para os estados conseguirem sanear suas empresas e colocá-las à venda foram realizados pelo BNDES, a partir de 1996, através do Convênio de Apoio ao Programa de Estímulo às Privatizações Estaduais (Pepe). Por esse programa, o BNDES emprestava recursos aos estados em troca da receita futura de privatização, com a garantia das ações da empresa (Leal, 1998).

Em março de 1996, o Executivo enviou à Câmara dos Deputados o Projeto de Lei no $1.669 / 96$, que propunha a criação da Aneel e do Conselho de Serviço Público de Energia, delimitava as atribuições da agência e especificava suas fontes de receita, sendo a principal delas a taxa de fiscalização. Esse projeto de lei não tratava da descentralização de forma detalhada. No seu art. $3^{\underline{0}}$, o projeto previa a articulação da União com os estados para a exploração de serviços e instalações de energia elétrica e o aproveitamento energético dos cursos de água e a possibilidade de credenciamento de órgãos estaduais para realizarem as atividades de fiscalização e controle dos serviços prestados nos seus territórios. Essa articulação entre União e estados estava prevista no art. 21 da Constituição Federal, segundo o qual a exploração de serviços e instalações de energia elétrica e o aproveitamento de cursos de água competem exclusivamente à União, mas ela deve atuar de forma articulada com os estados em que esses recursos se situam.

A exposição de motivos do anteprojeto de lei apresentado pelo ministro das Minas e Energia, à época o ministro Raimundo Brito, ao presidente da 
República, citava a possibilidade de descentralização, mas uma descentralização limitada aos termos do art. 21 da Constituição Federal e que parece preferir a delegação das atividades descentralizadas a empresas e consultores privados contratados pela agência, conforme seu item 9 (Câmara dos Deputados, 1996a):

A fim de proporcionar maior flexibilidade de atuação da agência, o anteprojeto prevê a delegação parcial de competência a órgãos existentes ou que venham a ser criados pelos estados, em função da articulação prevista na Constituição, além da possibilidade da execução de determinadas atividades, como, por exemplo, trabalhos de campo relativos a levantamento de dados e avaliações técnicas, mediante o credenciamento de técnicos e empresas especializadas.

O interesse dos estados na época da criação da Aneel não era apenas preservar o que a Constituição Federal já garantia, mas assegurar a manutenção do poder de fato que os estados exerciam sobre a distribuição dos serviços de energia com as empresas estaduais de energia elétrica. Como já foi dito, cerca de $80 \%$ da distribuição de energia estavam sob controle estadual.

O governo federal conseguiu aprovar a tramitação do projeto de lei em regime de urgência, garantindo uma tramitação mais rápida e a limitação na apresentação de emendas. A estratégia do relator, o deputado José Carlos Aleluia, era negociar o projeto com vários atores para apresentar um substitutivo representativo e fácil de aprovar no plenário (O Estado de S. Paulo, 1996). O substitutivo apresentado pelo relator em julho de 1996 ampliou a abrangência do projeto de lei, incluindo um capítulo tratando do regime econômico-financeiro das concessões e outro sobre licitações, e retirou o capítulo sobre o Conselho de Energia. Sobre a descentralização, o substitutivo manteve a previsão da articulação entre estados e União para o aproveitamento dos potenciais energéticos, mas excluiu qualquer referência à delegação de atividades de fiscalização e controle aos estados.

Foram apresentadas 34 emendas ao substitutivo, das quais o relator acatou apenas três. Uma das emendas incluía um capítulo sobre a descentralização das atividades de regulação para os estados e Distrito Federal, outra emenda incluía a previsão de articulação entre Aneel e ANP e a terceira emenda tratava das condições de renovação das concessões.

Na véspera da votação do projeto de lei na Câmara, foi realizada uma audiência pública na Comissão da Câmara de Trabalho, Administração e de Serviço Público com a presença dos deputados interessados e de vários especialistas na área, representando interesses distintos. Participaram dos deba- 
tes, entre outros, o vice-presidente da Associação Brasileira dos Grandes Consumidores de Energia (Abrace), o representante da Associação de Construtoras de Centrais Energéticas (ACCE), o representante da Associação Brasileira de Produtores Independentes de Energia Elétrica (Apine), bem como representantes do governo federal, como o secretário de Energia do Ministério de Minas e Energia, e dos governos e empresas estaduais, como os secretários de Energia dos estados da Bahia e de São Paulo (este último também era presidente do Fórum dos Secretários de Energia), e o presidente da Associação Nacional das Empresas Estaduais de Eletricidade (Câmara dos Deputados, 1996a).

A descentralização foi uma das questões levantadas no debate, e ficam claras as posições do governo federal e dos secretários estaduais de Energia. Os secretários de Energia de São Paulo e da Bahia apresentaram, em nome do Fórum dos Secretários para Assuntos de Energia, a reivindicação dos estados de autorização para fiscalizar as empresas concessionárias (O Estado de $S$. Paulo, 1996). O secretário de Energia do Ministério das Minas e Energia justificou a cautela do governo em relação à descentralização da fiscalização com base na preocupação com o descompasso entre a privatização das empresas estaduais de energia e a descentralização do poder de fiscalização dos serviços. O governo federal temia a possibilidade de os estados não desestatizarem o setor elétrico e continuarem com o poder de fiscalizar e de controlar os serviços, mantendo a situação de agentes que controlam a si próprios. Esse era um quadro a ser evitado, na visão do secretário de Energia do ministério. Já o secretário de Energia de São Paulo e então presidente do Fórum dos Secretários de Energia criticou abertamente a timidez do projeto de lei na promoção da descentralização e a sua exclusão do substitutivo.

No parecer sobre a apreciação das emendas, o relator, deputado José Carlos Aleluia, justificou a aceitação da emenda que incluía um capítulo sobre descentralização a partir das reivindicações dos secretários estaduais e com base nos debates da audiência pública. O substitutivo ao projeto de lei foi aprovado na Câmara com a previsão da descentralização da regulação para os estados, e enviado ao Senado em agosto de 1996. O projeto também tramitou em regime de urgência no Senado, onde foi aprovado, sem modificações, em dezembro de 1996, apesar das 14 emendas apresentadas.

O capítulo sobre descentralização da Lei $\mathrm{n}^{0}$ 9.427/96 define quais são as atividades descentralizadas e sua abrangência, prevê o acompanhamento da Aneel sobre essas atividades, explicita o poder complementar de regulação das unidades federativas e seu limite, e determina a repartição da taxa de fiscalização entre Aneel e estados. 
A redação final da lei criou a descentralização das "atividades complementares de regulação, controle e fiscalização dos serviços e instalações de energia elétrica". Estão excluídos da descentralização os serviços e instalações de geração de interesse do sistema elétrico interligado e os de transmissão integrante da rede básica. Isso faz sentido, dadas as características do sistema elétrico nacional, em que o governo federal controla cerca de $65 \%$ da geração e em que a rede de transmissão é integrada e gerida pelo governo federal.

O capítulo sobre descentralização prevê a exigência de requisitos técnicos e administrativos dos órgãos estaduais para poderem exercer as atividades descentralizadas, e prevê expressamente controle e acompanhamento da Aneel sobre seu desempenho. De acordo com resoluções da Aneel, esse controle é realizado pelo Convênio de Cooperação, do qual faz parte o Plano de Atividades e Metas (PAM). O convênio trata da abrangência das atividades descentralizadas e dos procedimentos financeiros relativos à repartição e administração da taxa de fiscalização. O PAM, de acordo com as resoluções $n^{0}$ 296 e nํㅡ 381 da Aneel, define as metas de fiscalização e de atuação das agências estaduais em relação às concessionárias e os procedimentos de prestação de contas das agências à Aneel.

Nenhuma outra agência federal tem um nível de descentralização de atividades semelhante ao da Aneel, e isso não decorre apenas da racionalidade técnica de um modelo de fiscalização descentralizado em um país de grande extensão como o Brasil, mas, principalmente, da articulação dos estados e das comunidades de energia das empresas estaduais em torno do interesse de manter o controle sobre a regulação e a fiscalização dos serviços de energia elétrica.

Outras agências federais celebram acordos de cooperação com agências subnacionais, mas nenhuma delas de forma sistemática como a Aneel. "A Aneel é a única agência na qual as atividades de descentralização são previstas e detalhadas na legislação e no regimento interno" (Melo, 2002: 262).

A ANP celebra convênios de cooperação com agências estaduais, mas esses convênios não abrangem as atividades de regulação nem de fiscalização, apenas a cooperação técnico-científica. O convênio da ANP regula a troca de informações entre os órgãos e não envolve partilha ou distribuição de recursos financeiros. A cooperação técnico-científica envolve a realização de estudos sobre aspectos tecnológicos e econômicos da regulamentação das atividades de transporte, distribuição e comercializa- 
ção do gás canalizado. Como as competências na área de gás canalizado estão divididas entre esferas federal e estadual (à primeira compete a produção e transporte e à segunda, a distribuição e comercialização do gás), a articulação entre as agências reguladoras é fundamental. A coordenação entre os organismos reguladores estaduais e federais é importante tanto na área técnica quanto na econômica, para, por exemplo, prevenir abusos nos setores monopolistas (transporte e distribuição) e garantir a qualidade do produto comercializado na ponta.

Essa análise do processo de aprovação da lei da Aneel demonstra como a definição do desenho institucional da agência, em especial a definição da descentralização de suas atividades de fiscalização e controle das empresas concessionárias, foi objeto de intensa disputa e negociação. A previsão inicial bastante restritiva da descentralização no projeto de lei e sua exclusão no substitutivo do relator da base aliada do governo mostram a intenção do governo federal de reduzir o poder de influência dos governos estaduais na regulação de energia.

A seguir será apresentado um panorama da descentralização na área de energia.

\section{A gestão da descentralização}

A atividade de regulação não foi descentralizada de fato, apesar de estar prevista na lei de criação da Aneel. Segundo entrevistados, os estados apenas participam da atividade de regulação pelo envio à Aneel de sugestões sobre novas regulamentações federais. Um exemplo desse tipo de interação foi a contribuição de São Paulo com o relatório sobre critérios de qualidade a serem exigidos pelos contratos de concessão dos serviços de distribuição de energia realizados pela Aneel. Esse relatório foi incorporado pela agência federal nos contratos realizados no país.

Desde 1998, a Aneel já firmou convênio de cooperação com 13 agências estaduais, para descentralizar as atividades de fiscalização e ouvidoria. Os primeiros convênios foram estabelecidos em 1998, e quatro estados já os renovaram, conforme o quadro 2 .

Em outubro de 2004 a Aneel divulgou um relatório em que apresenta dados quantitativos sobre a experiência de descentralização. $O$ âmbito de atuação das agências estaduais conveniadas abrange mais da metade da população

e do consumo de energia elétrica nacional. Os estados conveniados abrangem $60,8 \%$ da população, $69,2 \%$ do território nacional, $59,9 \%$ do consumo de energia elétrica e 59,45\% das unidades consumidoras (Aneel, 2004). 


\begin{tabular}{|c|c|c|}
\hline \multicolumn{3}{|c|}{ Quadro 2} \\
\hline $\begin{array}{l}\text { Unidade da } \\
\text { Federação }\end{array}$ & Agência conveniada & $\begin{array}{l}\text { Data da celebração } \\
\text { do convênio }\end{array}$ \\
\hline São Paulo & $\begin{array}{l}\text { Comissão de Serviços Públicos de Energia } \\
\text { (CSPE) }\end{array}$ & 15 de abril de $1998^{*}$ \\
\hline Rio Grande do Sul & $\begin{array}{l}\text { Agência Estadual de Regulação dos Serviços } \\
\text { Públicos Delegados do Rio Grande do Sul } \\
\text { (AGERGS) }\end{array}$ & 2 de dezembro de $1998^{*}$ \\
\hline Pará & $\begin{array}{l}\text { Agência Estadual de Regulação e Controle } \\
\text { de Serviços Públicos (Arcon) }\end{array}$ & 2 de dezembro de $1998^{*}$ \\
\hline Ceará & $\begin{array}{l}\text { Agência Reguladora de Serviços Públicos } \\
\text { Delegados do Estado do Ceará (Arce) }\end{array}$ & 19 de agosto de 1999 \\
\hline Rio Grande do Norte & $\begin{array}{l}\text { Agência Reguladora de Serviços Públicos } \\
\text { do Rio Grande do Norte (Arsep) }\end{array}$ & 15 de dezembro de $1999^{*}$ \\
\hline Bahia & $\begin{array}{l}\text { Agência Estadual de Regulação de Serviços } \\
\text { Públicos de Energia, Transporte e } \\
\text { Comunicações da Bahia (Agerba) }\end{array}$ & 2 de junho de 2000 \\
\hline Mato Grosso & $\begin{array}{l}\text { Agência Estadual de Regulação dos Serviços } \\
\text { Públicos de Delegados do Estado de Mato } \\
\text { Grosso (Ager) }\end{array}$ & 2 de julho de 2001 \\
\hline Pernambuco & $\begin{array}{l}\text { Agência de Regulação dos Serviços Públicos } \\
\text { Delegados do Estado de Pernambuco (Arpe) }\end{array}$ & 16 de abril de 2002 \\
\hline Alagoas & $\begin{array}{l}\text { Agência Reguladora de Serviços Públicos } \\
\text { do Estado de Alagoas (Arsal) }\end{array}$ & 17 de abril de 2002 \\
\hline Goiás & $\begin{array}{l}\text { Agência Goiana de Regulação, Controle e } \\
\text { Fiscalização de Serviços Públicos (AGR) }\end{array}$ & 16 de maio de 2002 \\
\hline Mato Grosso do Sul & $\begin{array}{l}\text { Agência Estadual de Regulação de Serviços } \\
\text { Públicos do Mato Grosso do Sul (Agepan) }\end{array}$ & 7 de junho de 2002 \\
\hline Paraíba & Agência Estadual de Energia da Paraíba (Ageel) & 27 de junho de 2002 \\
\hline Amazonas & $\begin{array}{l}\text { Agência Reguladora de Serviços Públicos } \\
\text { Concedidos do Estado do Amazonas (Arsam) }\end{array}$ & 3 de julho de 2002 \\
\hline
\end{tabular}

Rap Rio de Janeiro 40(4):567-88, Jul./Ago. 2006 
As atividades descentralizadas são financiadas pela taxa de fiscalização, recolhida pelos concessionários, permissionários e autorizados e repassada pela Aneel. Entre 1998 e 2004, a Aneel repassou pouco mais de R\$ 80 milhões às agências conveniadas.

O processo de descentralização foi paralisado a partir de 2003, devido à mudança de orientação do governo em relação à expansão do modelo de agências. Essa paralisação se expressou, principalmente, no contingenciamento do orçamento da Aneel, reduzindo sua capacidade de ampliar o número de agências conveniadas. Como se pode ver na tabela 2, os recursos efetivamente repassados começaram a diminuir a partir de 2003, por efeito do contingenciamento de cerca de $50 \%$ do montante aprovado no orçamento.

\begin{tabular}{|lcc|}
\hline \multicolumn{3}{|c|}{ Tabela 2} \\
Valores dos repasses às agências estaduais pela Aneel \\
entre 1998 e 2004
\end{tabular}

O relatório avalia positivamente a descentralização da fiscalização, com base na melhoria dos índices de qualidade no fornecimento de energia elétrica e do atendimento dos usuários. Os índices de qualidade mais usados na área de energia elétrica são duração equivalente de interrupção por unidade consumidora, medido em horas (DEC) e freqüência equivalente de interrupção por unidade consumidora, que mede o número de interrupções (FEC). De fato, todos os estados conveniados melhoraram seus índices de qualidade entre 1996 e 2003. A DEC e a FEC caíram, ou seja, a prestação dos serviços melhorou em todos os estados, conforme tabela 3. 


\begin{tabular}{|c|c|c|c|c|c|c|}
\hline & \multicolumn{6}{|c|}{$\begin{array}{c}\text { Valores absolutos e variação proporcional de DEC e FEC } \\
\text { entre } 1996 \text { e } 2003 \text { nos estados conveniados }\end{array}$} \\
\hline Estado & $\begin{array}{l}\mathrm{DEC}^{2} \\
1996\end{array}$ & $\begin{array}{l}\text { DEC } \\
2003\end{array}$ & $\begin{array}{l}\text { Variação no } \\
\text { período (\%) }\end{array}$ & $\begin{array}{l}\mathrm{FEC}^{3} \\
1996\end{array}$ & $\begin{array}{l}\text { FEC } \\
2003\end{array}$ & $\begin{array}{l}\text { Variação no } \\
\text { período (\%) }\end{array}$ \\
\hline AM & 74 & 37 & 50,0 & 62 & 38 & 38,7 \\
\hline PB & 63 & 24 & 61,9 & 41 & 10 & 75,6 \\
\hline MS & 22 & 11 & 50,0 & 14 & 10 & 28,6 \\
\hline G0 & 48 & 23 & 52,1 & 61 & 24 & 60,7 \\
\hline$A L^{1}$ & 44 & 28 & 36,4 & 26 & 22 & 15,4 \\
\hline PE & 17 & 13 & 23,5 & 15 & 9 & 40,0 \\
\hline MT & 88 & 24 & 72,7 & 133 & 26 & 80,5 \\
\hline BA & 29 & 16 & 44,8 & 13 & 11 & 15,4 \\
\hline RN & 50 & 11 & 78,0 & 41 & 9 & 78,0 \\
\hline CE & 32 & 16 & 50,0 & 34 & 16 & 52,9 \\
\hline PA & 60 & 30 & 50,0 & 52 & 32 & 38,5 \\
\hline RS & 29 & 22 & 24,1 & 30 & 16 & 46,7 \\
\hline $\mathrm{SP}$ & 14 & 8 & 42,9 & 9 & 6 & 33,3 \\
\hline \multicolumn{7}{|c|}{$\begin{array}{l}\text { Fonte: Aneel, } 2004 . \\
1 \text { Valores de } 1997 \text { e } 2003 . \\
2 \text { Medido em horas. } \\
{ }^{3} \text { Medido em número de interrupções. }\end{array}$} \\
\hline
\end{tabular}

O relatório não faz uma avaliação sobre a confiabilidade dos valores da DEC e da FEC dos estados, que são fornecidos pelas empresas concessionárias, ou seja, pelos próprios fiscalizados. Segundo Pires (2000:41):

é necessário que a Aneel aprimore a fiscalização dos contratos de concessão para garantir a qualidade dos serviços, incluindo o desenvolvimento de modelos de controle da qualidade de energia por meio de sistemas de medição independentes dos realizados pelas empresas como, por exemplo, a ampliação do sistema Argos, que hoje cobre apenas mil consumidores distribuídos em cinco estados (Pará, Bahia, Rio de Janeiro, São Paulo e Rio Grande do Sul), pelo qual, por meio de aparelhos conectados a telefones, são registradas automaticamente na Aneel falhas no fornecimento de energia, sem depender das informações das operadoras.

Além disso, o relatório não problematiza as grandes diferenças regionais nos níveis absolutos dos indicadores. Há uma enorme variação de qualidade na prestação do serviço entre os estados, conforme as tabelas 4 e 5 . 


\begin{tabular}{|lcc|}
\hline \multicolumn{4}{c|}{ Tabela 4} \\
\multicolumn{2}{|c|}{ Variação da DEC entre os estados conveniados } \\
\hline Estado & DEC 2003 & Variação entre estados \\
\hline AM & 37 & 462,5 \\
PA & 30 & 375 \\
AL & 28 & 350 \\
PB & 24 & 300 \\
MT & 24 & 300 \\
GO & 23 & 287,5 \\
RS & 22 & 275 \\
BA & 16 & 200 \\
CE & 16 & 200 \\
PE & 13 & 162,5 \\
MS & 11 & 137,5 \\
RN & 11 & 137,5 \\
SP & 8 & 100 \\
\hline
\end{tabular}

\begin{tabular}{|lcc|}
\hline \multicolumn{4}{|c|}{ Tabela 5} \\
& Variação da FEC & \\
\hline Estado & FEC 2003 & Variação entre estados \\
\hline AM & 38 & 633,3 \\
PA & 32 & 533,3 \\
MT & 26 & 433,3 \\
GO & 24 & 400,0 \\
AL & 22 & 366,7 \\
CE & 16 & 266,7 \\
RS & 16 & 266,7 \\
BA & 11 & 183,3 \\
PB & 10 & 166,7 \\
MS & 10 & 166,7 \\
PE & 9 & 150,0 \\
RN & 9 & 150,0 \\
SP & 6 & 100,0 \\
\hline
\end{tabular}

RaP Rio de Janeiro 40(4):567-88, Jul./Ago. 2006 
Segundo um entrevistado, a Aneel tem ojeriza a regionalizar e diferenciar a regulação entre os estados. A tendência da atuação da Aneel tem sido no sentido de uniformizar as regras entre os estados, o que tem gerado efeitos negativos em alguns casos, como nos exemplos do Termo de Ajustamento de Conduta (TAC) e do Procedimento de Indenização de Danos (PID).

O TAC e o PID foram instrumentos criados pela agência reguladora de São Paulo, com o aval da Aneel, para agilizar sua atuação, respectivamente, na área de fiscalização e de mediação. O TAC é um instrumento jurídico no qual se privilegiam exigências do cumprimento de metas para melhoria da qualidade por parte da concessionária que transgrediu os padrões de qualidade e que apresenta justificativas atenuantes, ou seja, é um acordo pelo qual uma multa imposta pela agência estadual à empresa concessionária pode ser convertida em investimento pela empresa, desde que o problema que tinha gerado a aplicação da multa esteja ligado à operação dos serviços, e não a irregularidades econômico-financeiras. Esse procedimento permitia a aplicação do valor da multa em atividade operacional relacionada ao problema que gerou a autuação, aumentando o investimento da empresa além do estabelecido nos contratos e promovendo a adequação dos serviços mais rapidamente. Há cerca de dois anos, a Aneel regulamentou o TAC, centralizando em Brasília a decisão sobre sua aplicação em todos os estados. A morosidade gerada pela avaliação de todos os processos do país por uma única instância tornou o TAC um instrumento, na prática, inócuo.

Outro exemplo de uniformização de procedimentos pela Aneel que reduziu seu potencial de aplicação foi a regulamentação do PID. O Procedimento de Indenização de Danos foi uma forma de a agência paulista mediar as relações entre concessionárias e consumidores nos casos de danos provocados a aparelhos eletrodomésticos por variações de tensão no fornecimento de energia. De acordo com o PID, as concessionárias tinham poucos dias para verificar se a reclamação do consumidor era procedente, ou seja, se o dano era devido a problemas no fornecimento de energia, e deveriam ressarcir o consumidor imediatamente. A regulamentação da Aneel ampliou o prazo para as concessionárias responderem ao consumidor para três meses, dentro dos quais o consumidor não pode providenciar o conserto ou troca do aparelho danificado, sob pena de perder o direito ao ressarcimento. Ou seja, para uniformizar a regra entre todos os estados, que, como vimos, têm padrões de qualidade muito diferentes entre si, a Aneel reduziu drasticamente a efetividade desse instrumento.

Além da fiscalização, outra atividade objeto da descentralização é a ouvidoria. As agências estaduais conveniadas devem criar instrumentos próprios de atendimento aos consumidores finais, bem como fiscalizar o atendimento pres- 
tado pelas concessionárias. Nesse aspecto, o relatório da Aneel faz uma avaliação superficial, afirmando como positiva a experiência, sem analisar as políticas de relacionamento entre agências e concessionárias e os consumidores.

Segundo entrevista com profissionais que atuam em órgãos de proteção ao consumidor, a descentralização da ouvidoria para as agências estaduais é positiva, pois aumenta a proximidade da agência com o consumidor, permitindo a identificação mais precisa do perfil do consumidor e a coleta de mais informações, essenciais para o desenvolvimento de meios de ação mais eficazes e para aumentar a agilidade da agência em questões emergenciais, como foi o caso da crise energética de 2001. Apesar disso, a agência e as empresas concessionárias devem ter políticas de relacionamento com o cliente definidas e transparentes. Não foi possível, nos limites deste artigo, avaliar mais profundamente a medida em que as agências conveniadas mantêm e fiscalizam políticas de relacionamento com o consumidor.

O Instituto Brasileiro de Defesa do Consumidor (Idec) faz uma avaliação sobre a atuação das agências federais, na qual a Aneel se destaca nos critérios de publicidade e transparência. Entretanto, não é possível verificar se esse desempenho se repete nas agências estaduais conveniadas.

Avaliação do Idec sobre as agências reguladoras federais

\begin{tabular}{|c|c|c|c|c|c|c|}
\hline & \multicolumn{4}{|c|}{ Avaliação da configuração institucional e transparência } & \multirow[b]{2}{*}{$\begin{array}{l}\text { 5. Avaliação } \\
\text { da } \\
\text { efetividade } \\
\text { em } \\
\text { prol do } \\
\text { consumidor }\end{array}$} & \multirow[b]{2}{*}{ Fina } \\
\hline & $\begin{array}{l}\text { 1. Existência } \\
\text { de canais } \\
\text { institucionalizados } \\
\text { e condições } \\
\text { para a } \\
\text { participação dos } \\
\text { consumidores }\end{array}$ & $\begin{array}{l}\text { 2. Transparência } \\
\text { de atos, } \\
\text { procedimentos } \\
\text { e processos } \\
\text { decisórios }\end{array}$ & $\begin{array}{l}\text { 3. Acesso à } \\
\text { informação, } \\
\text { legislação, } \\
\text { dados do setor } \\
\text { regulado, } \\
\text { atividades e } \\
\text { resultados da } \\
\text { ação dos órgãos }\end{array}$ & $\begin{array}{l}\text { 4. Publicidade } \\
\text { do órgão e } \\
\text { mecanismos } \\
\text { para recebimento e } \\
\text { resolução de pro- } \\
\text { blemas dos consu- } \\
\text { midores }\end{array}$ & & \\
\hline Inmetro & 6,0 & 5,0 & 8,8 & 6,8 & 6,0 & 6,3 \\
\hline Aneel & 4,0 & 8,8 & 6,8 & 8,3 & 4,5 & 5,8 \\
\hline Anvisa & 5,8 & 5,0 & 6,0 & 6,3 & 5,5 & 5,6 \\
\hline Anatel & 4,8 & 8,0 & 5,5 & 6,8 & 3,5 & 4,9 \\
\hline ANS & 5,8 & 3,0 & 5,8 & 6,8 & 1,5 & 3,3 \\
\hline SDA & 0,0 & 1,3 & 3,3 & 0,0 & 4,0 & 2,7 \\
\hline $\begin{array}{l}\text { Banco } \\
\text { Central }\end{array}$ & 0,0 & 2,0 & 5,3 & 5,3 & 2,0 & 2,6 \\
\hline
\end{tabular}




\section{Avaliação das agências e órgãos - nota final}

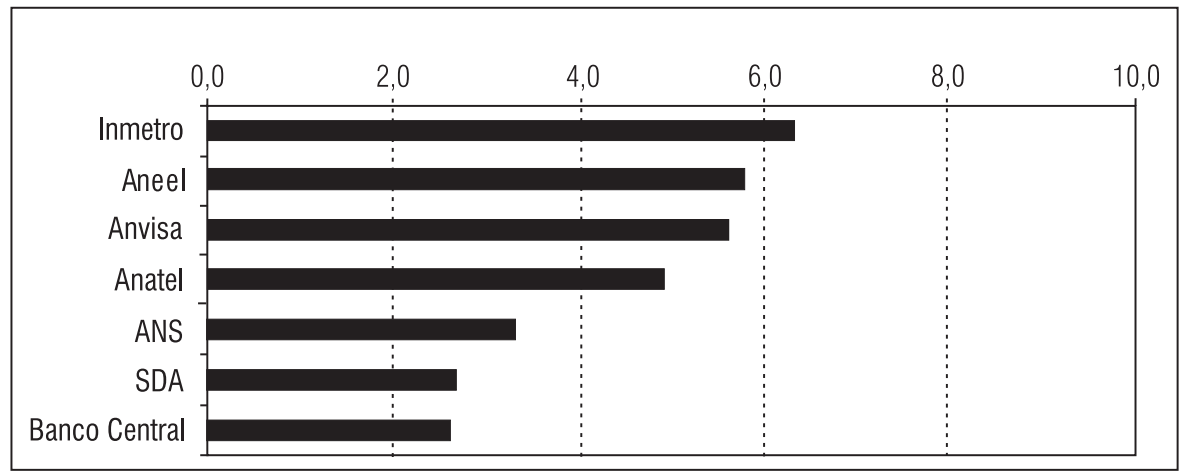

Fonte: Idec, 2004:32

\section{Referências bibliográficas}

ANEEL (AGÊNCIA NACIONAL DE ENERGIA ELÉTRICA). Relatório descentralização - dados e fatos. Brasília: Superintendência de Relações Institucionais, Aneel, 2004.

CÂMARA DOS DEPUTADOS. Exposição de motivos nํㅡ 011/MME. Diário da Câmara dos Deputados, Brasília, p. 08939, 9 abr. 1996a.

. Audiência pública da Comissão de Trabalho, Administração e Serviço Público no 0592/96. 23 jul. 1996b.

CONFORTO, G. A regulação e a titularidade dos serviços de abastecimento de água e esgotamento sanitário no Brasil. RAP, Rio de Janeiro: FGV, v. 34, n. 5, set./out. 2000.

O ESTADO DE S. PAULO. Estados poderão fiscalizar empresas de energia. 24 jul. 1996. p. B8.

FERREIRA, F. M. Regulação por contrato no setor de saneamento: o caso de Ribeirão Preto. 2005. Dissertação (Mestrado) — Escola de Administração de Empresas de São Paulo, Fundação Getulio Vargas, São Paulo.

IDEC (INSTITUTO DE DEFESA DO CONSUMIDOR). Avaliação das agências reguladoras e outros órgãos governamentais. São Paulo: Idec, 2004.

LEAL, C. F. C. Ágios, envelopes e surpresas: uma visão geral da privatização das distribuidoras estaduais de energia elétrica. Revista do BNDES, n. 10, dez. 1998.

MELO, M. A. As agências regulatórias: gênese, desenho institucional e governança. In: ABRUCIO, F.; LOUREIRO, M. R. O Estado numa era de reformas: os anos FHC. São Paulo: Annablume, 2002. 
PIRES, J. C. L. Desafios da reestruturação do setor de energia elétrica brasileiro. Rio de Janeiro: BNDES, 2000. (Textos para discussão BNDES, n. 76).

PNAGE (PROGRAMA NACIONAL DE APOIO À GESTÃO DOS ESTADOS BRASILEIROS). Diagnóstico geral das administrações públicas estaduais. 2003. Disponível em: <www.consad. org.br/Doc/DiagnosticoGeralAdministracoesEst.pdf>. Acesso em: 2004.

Rap Rio de Janeiro 40(4):567-88, Jul./Ago. 2006 